\title{
Post-Pandemic Research Innovations Contributing to Economic Development
}

\author{
Beth A. Montelone, PhD \\ Senior Associate Vice President for Research \\ Kansas State University \\ 102 Fairchild Hall \\ 1601 Vattier Street \\ Manhattan, KS 66506 \\ https://orcid.org/0000-0003-2992-4007
}

7 he COVID-19 pandemic had an undoubted effect on university research, with most U.S. institutions temporarily shutting down most on-site research activities in March 2020 for three months or more, followed by a slow and phased approach to reopening (Wigginton et al, 2020).

At Kansas State University, nearly all research "hibernated," apart from activities deemed essential to complete ongoing, time-sensitive studies or infectious disease work at our College of Veterinary Medicine and Biosecurity Research Institute (BRI). Hibernation lasted from March through the end of June 2020. During this time, work at the BRI, a BSL3 and BSL3-Ag facility, largely pivoted as studies were completed to new projects on SARS-CoV-2, once the viral sequence and samples became available.

The BRI also reached an agreement with the Kansas Department of Health and Environment (KDHE) and the Kansas State Veterinary Diagnostic Lab (KSVDL) for KSVDL personnel to use BSL-3 lab space to begin conducting SARS-CoV-2 screening to enhance KDHE's capacity.

\section{Research Reawakening}

As the State of Kansas began planning for a phased reopening of businesses temporarily shuttered by the stay-athome order imposed at the start of the pandemic, K-State units did likewise. The Office of the Vice President for Research, in conjunction with the Associate Deans for Research of the larger, more research-active colleges, developed detailed plans for "reawakening" research, with a phased approach matching the
University-wide plans and reflecting the State of Kansas timing.

The State reopening began in June 2020. In the first month, the so-called Phase 2, strict occupancy limitations and social distancing guidelines constrained research activities both in laboratories and in field settings. In addition, for the duration of the reawakening Phases 2 and 3 , the latter of which did not end until the summer of 2021, particular research activities were not allowed, specifically:

- Adding new undergraduate researchers to lab-based studies; and

- Face-to-face human subjects research.

Needless to say, both of these strictures and other constraints negatively impacted some research studies.

Metrics Around COVID-19/ Pandemic Impacts

There are multiple ways to parse the impact upon research of the pandemic and research hibernation. One is to ask what benefits accrued. When federal funding became available in spring 2020 for research on the novel coronavirus, K-State started tagging proposals related in some way to the virus, its impacts on health and society, and on possible ways to ameliorate the latter. To date, K-State 
has received over \$21 million in funding, specifically for work on SARS-CoV-2testing, disinfection, basic research, and countering economic impacts, exclusive of the CARES Act Higher Education Emergency Relief Fund funding to the University.

The impacts of the hibernation of most active research and subsequent slow resumption, coupled with continuing K-12 school closures, have yet to be fully analyzed at most institutions and nationally. There has been speculation that researcher productivity would be negatively impacted, particularly for researchers who were parents, and that women might disproportionately be affected (Collins, 2020). Subsequent analyses discussed these issues in more detail, including effects on underrepresented minority researchers and have suggested strategies for ameliorating the negative impacts (Carr et al, 2021). K-State has not yet done an in-depth study into these questions.

In terms of research productivity writ large, we have compared proposals and awards for the last five fiscal years broken out by quarter. Figure 1A shows that while FY 2021 (July 1, 2020-June 30, 2021) had a lower total dollar amount in proposed activities than FY 2020, which was a new high for K-State, most of the record-setting total for FY 2020 can be attributed to the first quarter. Furthermore, the last quarter of FY 2020, corresponding to the hibernation period, had a lot of proposal activity. Of course, proposal activity is largely dependent on what funding opportunities arise during each quarter/fiscal year, in addition to the time researchers spend on submitting proposals.

Figure 1B shows that both FY 2020 and FY 2021 easily eclipsed the prior years in terms of award dollars. Again,

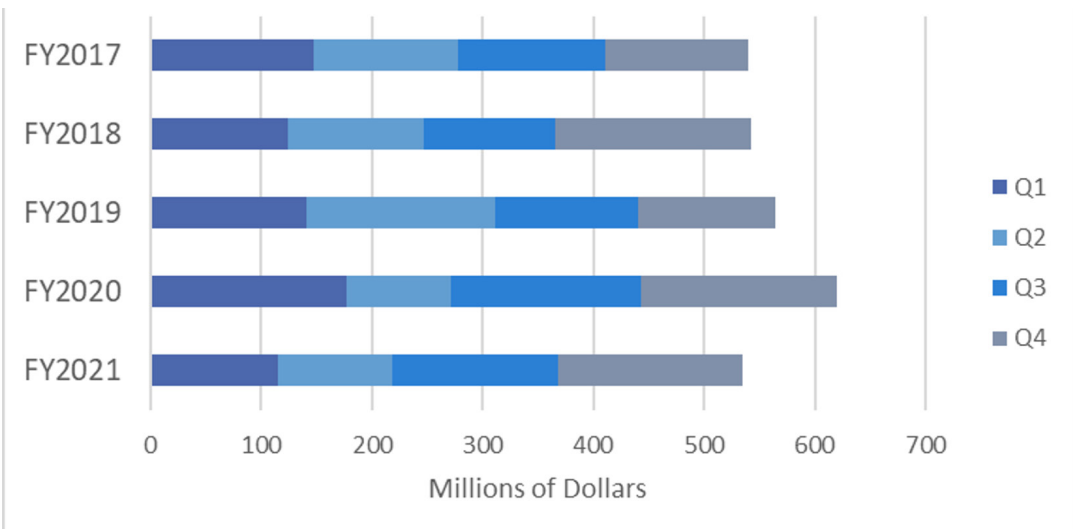

Figure 1A. Proposal activity in dollars for fiscal years 2017-2021.

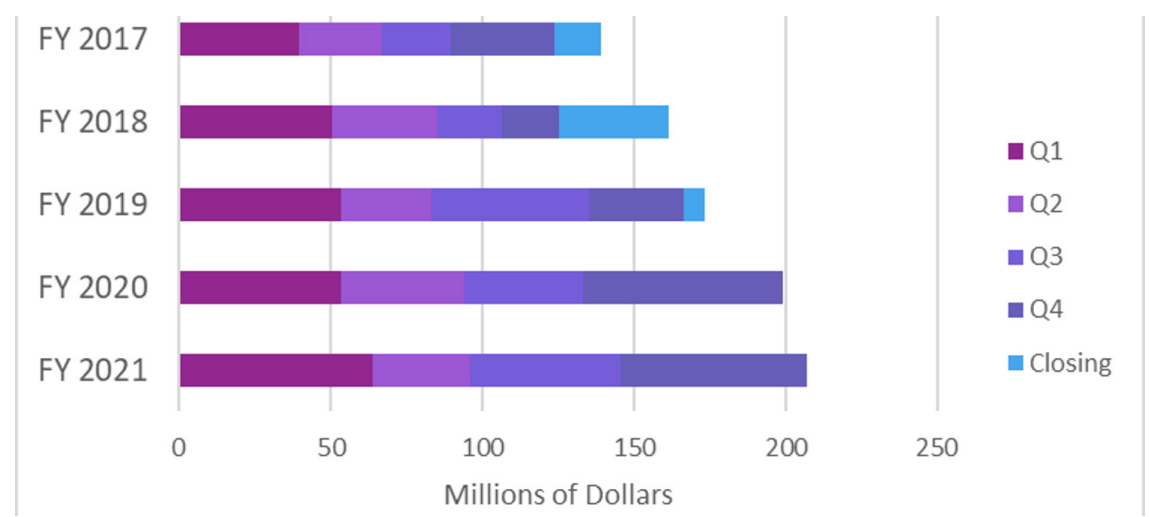

Figure 1B. Award activity in dollars for fiscal years 2017-2021. 
this is partly dependent on the periodicity of funding opportunities and the renewal cycles for existing large program projects. Both FY 2020 and FY 2021 totals include the Higher Education Emergency Relief Fund awards that came in as sponsored projects to the university.

Where do we go from here?

As the nation moves in halting steps away from the COVID-19 pandemic, researchers and research administrators are looking to the future. Many of the recently released and forthcoming opportunities authorized under the American Recovery Plan seek to rebuild and strengthen the economy. This is coupled with an increasing trend of state and local governments looking to universities, particularly research universities, as engines of economic development.

K-State will continue to build on our traditional strength areas, particularly in the natural sciences, engineering, and agriculture; foster interdisciplinary work; and adhere to our land-grant mission to support communities and the state with innovations promoting economic prosperity. Our blueprint for the future in this area is articulated in our response to the 2020 strategic plan from the Kansas Board of Regents (KBOR), Building a Future (KBOR, 2020).

This document defines three so-called pillars:

1. Helping Kansas Families

2. Supporting Kansas Businesses

3. Advancing Kansas Economic Prosperity

Universities have historically worked to provide trained workers to fill jobs dictated by the economic conditions at the time. KBOR, with its articulation of Pillar 3, seeks to advance the creation of jobs and direct investments beyond state borders. Creating the jobs of the future will require:

- Alignment of education and local, state and federal government;
- Partnerships with private business, industry and investors;

- Actively working, engaging, and leveraging the attraction of investment capital in Kansas' core strength areas; and

- Infrastructure investments, including in people, process, information, and technology (e.g., broadband).

KBOR made Pillar 3 a charge for the six Kansas Regents universities, with the responsibility for Pillar 3 initiatives residing with the university CEOs, and they went further to identify the leads for Pillar 3 working groups at each university. K-State's Pillar 3 planning team was then-Vice President for Research Peter Dorhout, K-State Foundation CEO Greg Willems, and K-State Innovation Partners CEO Kent Glasscock. The charge from KBOR stressed that proposed programming and strategies must be focused on the two key metrics of jobs and investments.

K-State chose four focus areas for our Pillar 3 plan, reflecting our land-grant mission and the disciplinary areas in which we have primarily benefited from partnerships with the private sector:

1. Food and Agriculture Systems Innovation

a. Will build on our historic strengths in advanced breeding techniques and integrated cropping systems.

2. Digital Agriculture and Advanced Analytics

a. Will exploit existing computing capacity, work with artificial intelligence systems and precision agriculture.

b. Will take advantage of the geographic one of a range of climatic zones across the state that mimic many of the significant agricultural regions globally. 
3. Biosecurity and Biodefense

a. Will leverage BSL-1 through BSL-4 assets on and adjacent to campus and our partnership with USDA facilities, including the National Bio- and Agro-Defense Facility.

4. K-State 105

a. Will build on the statewide research and extension network and its presence in all 105 Kansas counties to create a statewide economic development network.

\section{Food and Agriculture Systems} Innovation

- New scalable multi-disciplinary links to enable sustainable systems-level food and ag research.

- Potential innovations in alternative crop development, value-added opportunities, and ag tech innovation and applications.

The Kansas Framework for Growth (KS Department of Commerce, 2021) focuses on five tradable industries. Kansas is twice as specialized as the national average in one of these industries: food and agriculture. The Framework for Growth specifically calls out leading higher education institutions specializing in food and agriculture to utilize extension systems and research facilities to make Kansas "a world-class home to research, development, and testing of new technologies in animal health, crop science, ag-tech and data analytics." This proposal directly responds to all four Kansas Framework for Growth strategic pillars (talent, innovation, community assets, and policy) and how the shared strategies are seeking value-added opportunities, ag tech innovation, sustainability initiatives, and the targeted support of producers.

The Food and Ag Systems focus area proposes a stakeholder-driven, systems-level strategy that includes a transdisciplinary team of researchers, as well as regular engagement with an advisory board to identify appropriate opportunities and venues. Partners across food and agriculture systems will include industries, producers, processors, regional foundations, commodity and trade organizations, as well as federal and state government. Consumers will be involved at both ends of the food production pathway.

The desired outcomes of these activities are:

1. Stimulation of economic growth and job creation;

2. Establishment of profitable, regenerative, and sustainable food and agriculture systems;

3. Fostering of disruptive technology and innovation; and

4. Improvement of Kansas community health through nutritional security.

Digital Agriculture and Advanced Analytics (DAAA)

- Artificial intelligence for production agriculture.

- Scale-independent precision agriculture, current and emerging threats to crops and precision livestock production.

This focus envisions the incorporation of existing K-State expertise in advanced breeding techniques and integrated cropping systems research to better attract opportunities and establish strategies that grow the capabilities and capacity needed to firmly establish K-State

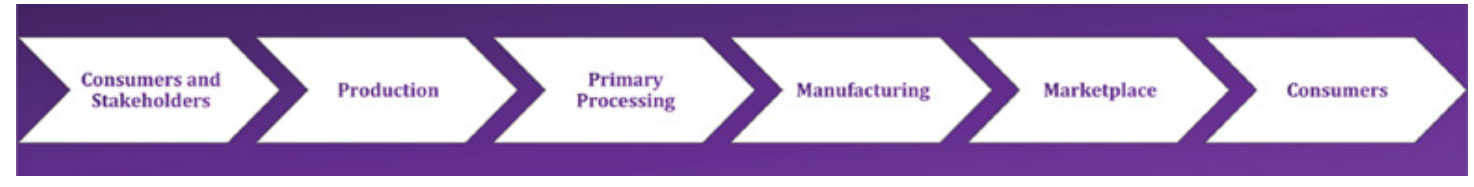


as a global leader in DAAA. It draws on expertise from multiple K-State colleges to firmly establish K-State as a true "cyber-land grant" institution.

Kansas is uniquely positioned to serve as a DAAA development hub. The extreme variability of climatic and production conditions found in Kansas positions the state as an analog for a significant portion of U.S. and global dryland and irrigated agricultural regions (Figures $2 \mathrm{~A}$ and $2 \mathrm{~B}$; images from Kottek et al., 2006).

K-State's distribution of regional research and extension centers (Figures 3A and $3 \mathrm{~B}$ ) span this climatic gradient, making it an ideal laboratory for developing DAAA in the most variable and challenging environments.

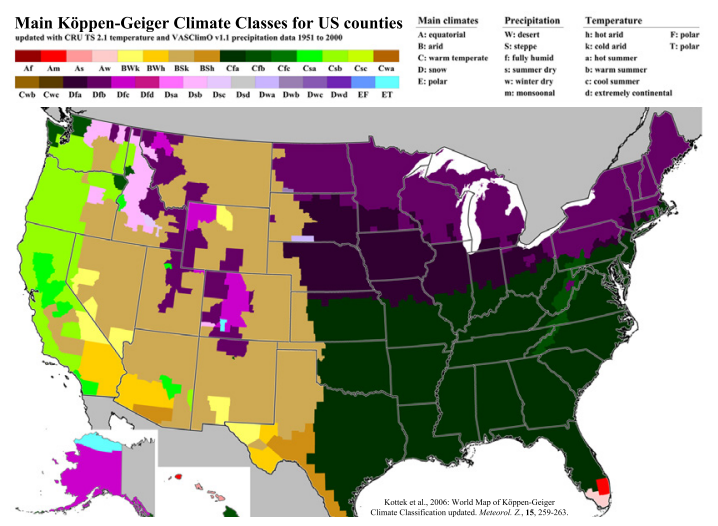

Figure 2A. Climatic zones of the US.

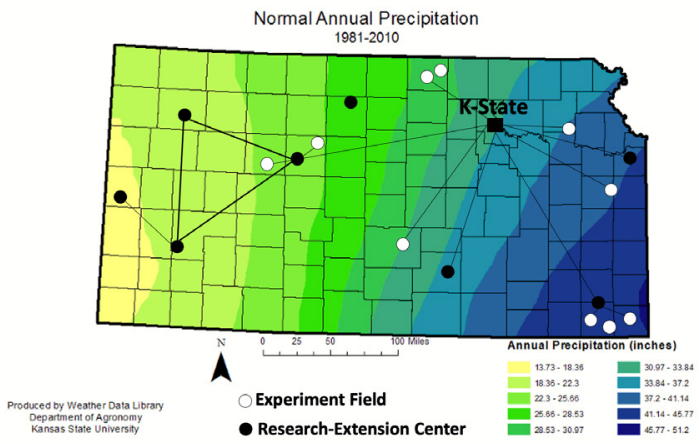

Figure 3A. Precipitation gradient across KS superimposed with locations of experiment fields and research-extension centers. Data from Weather Data Library, Department of Agronomy, Kansas State University.
Additionally, K-State owns or leases nearly 30,000 acres of land dedicated to DAAA throughout the state, including the Lonsinger Sustainability Farm, to inform sustainable, resilient, climate-smart crop and livestock research and development.

\section{Biosecurity and Biodefense}

- K-State will add a Biologics Development Module under BSL-3 containment to the BRI, enabling private sector vaccine/therapeutics manufacturers and their university researcher partners a pilot production facility.

$\mathrm{K}$-State has made significant investments in biosecurity and biodefense and is currently the only university in the world at which researchers have access to a full spectrum of BSL1-4 facilities lo-

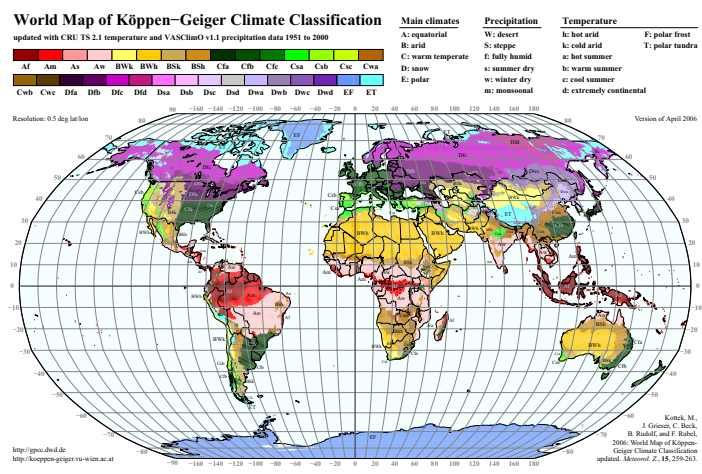

Figure 2B. Climatic zones of the world.

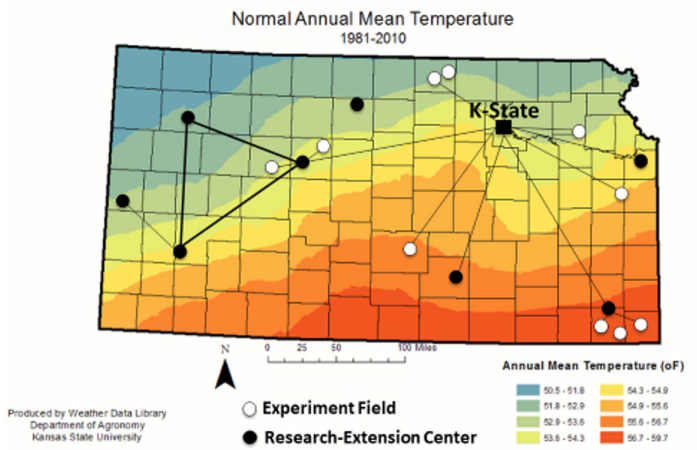

Figure 3B. Temperature gradient across KS superimposed with locations of experiment fields and research-extension centers. Data from Weather Data Library, Department of Agronomy, Kansas State University. 
cated on or adjacent to campus. BSL1-3 spaces exist on the Manhattan campus, with most of the latter at the Biosecurity Research Institute (BRI). The BSL-4 USDA National Bio- and Agro-Defense Facility (NBAF) is located immediately adjacent to the BRI and has established a number of partnerships and cooperative agreements with K-State units and individual researchers.

While extensive, K-State's biocontainment capacity for intellectual discovery at these facilities is not sufficient to advance economic development. We propose to address this by adding a Biologics Development Module to the BRI. This BSL-3 facility strategy will increase capacity for commercialization and manufacturing to ensure technological advancements are utilized in practical application. This structure will streamline the discovery to commercialization process for industry partners by reducing the regulatory burden associated with conducting containment/non-containment and live animal/ benchtop research at multiple institutions. The extensive talent and infrastructure in Manhattan will attract companies, entrepreneurs and venture capitalists to the region. New technology will be developed for economically important plant, animal, and zoonotic infectious diseases. No other university will have comparable assets.

During the COVID-19 pandemic K-State has been in a unique position to pivot research and contribute solutions for global human health using existing resources. The BRI was instrumental in securing for K-State $\$ 12$ million in funded grants, as well as several licensing agreements related to COVID-19. The notable limitation was the capacity for commercialization at this facility. The proposed strategies will allow K-State to become the foremost U.S. resource to facilitate private-public collaboration for research on pathogens of worldwide significance. These assets will strengthen relationships with industry and increase access to export markets for food and agricultural products. K-State's collective expertise in vaccine development, regulatory affairs and flexible manufacturing capacity will not exist anywhere else in the world. A global reputation for success in discovery and commercialization will enhance our opportunities to attract corporate pharmaceutical partners, licensing agreements, and workforce talent.

\section{K-State 105}

K-State will augment its presence in 105 counties in Kansas, creating an "Every Town to Gown" initiative designed to deploy cutting-edge research and development, workforce development initiatives, and new practices that solve relevant problems, support community and economic development, and encourage connectivity between urban and rural areas. K-State will establish streamlined mechanisms for businesses and communities across the state to access our innovation, talent, and training through local liaisons and coordinated resources. This initiative will further our status as a leader in community vitality and focus on creating sustainable growth across the state.

With research centers, experiment fields, and extension services throughout the state, K-State's campus literally extends to every county in Kansas. While our statewide presence and network already attracts state, federal, and private funding, strategically leveraging this core capacity will attract additional investment and corporate partners seeking to build their workforce and advance the development of new innovations. From local rural communities to state-of-theart laboratories, our network connects resources to regional needs and opportunities. K-State 105 promotes local collaboration and investments in the human, social, and financial capital of our Kansas communities.

Our statewide research presence, combined with the climate and soil vari- 
ability across the state, provides unique opportunities for agricultural research. K-State can be expected to achieve this aspirational goal because of our well-established network of highly respected Extension professionals throughout the state, as well as through partnerships with existing state and local economic development professionals.

Initial phases will utilize existing resources to convene stakeholders to better understand statewide needs and match relevant university resources to assist with targeted solutions. The goal of these efforts is to have our existing resources engage communities at a deeper level to identify challenges they are facing and bring them forward to determine if K-State resources can be used to assist in accomplishing their goals. Later phases will include adding dedicated liaisons and more effectively coordinated operational units to deploy needs-based solutions. As these phases are deployed, the university will examine existing engagement processes and alter them in ways that streamline the engagement pipeline.

In order for aggressive implementation to occur, the K-State 105 initiative will require external resources, particularly to fund the convening and coordination capacity needed to truly leverage K-State's existing presence in 105 counties and the centralized resources that can support statewide needs. In addition to investment from federal, state, local, private industry, and nonprofits, this initiative will require a commitment from communities and regions, as well as uni- versity stakeholders and partners. Public and private partners who will help execute the strategies, include, but are not limited to:

- Small Business Development Center (SBDC) - Coordinate small business and entrepreneur research and technical assistance needs with university.

- Kansas Department of Agriculture (KDA) - Coordinate the implementation of the Kansas Agriculture Growth Strategy.

- Kansas Department of Commerce - As the state's lead economic development agency, administer programs and services to support businesses, grow the economy, and improve quality of life across the state.

- NetWork Kansas - Leverage statewide network of non-profit business building resources to assist small businesses and entrepreneurs.

- Kansas Board of Regents (KBOR) - Coordinate on the implementation of strategic initiatives across the Pillar 3 Economic Prosperity focus of the KBOR strategic plan.

- Business Resources for Innovation and Exporting (BRITE) Center - Assist in matching regional needs with resources, including access to capital.

- Local Economic Development Partners - Partner with local county Extension to identify regional needs and opportunities related

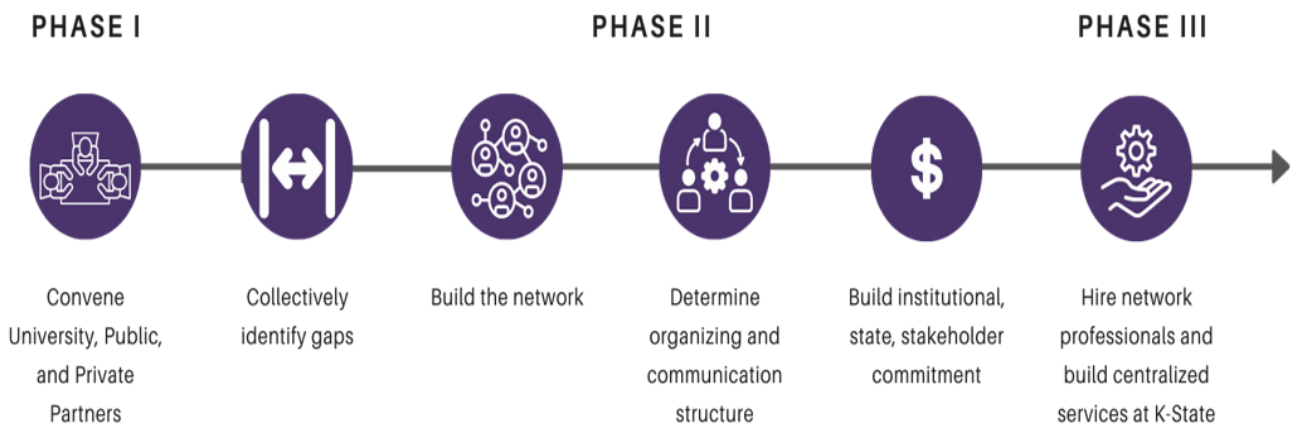


to business recruitment, retention, and growth, as well as workforce development and community vitality needs.

Our Pillar 3 focus area development activities were built upon the process followed during our successful pursuit of the prestigious Association of Public and Land-grant Universities Innovation $\mathcal{E}$ Economic Prosperity designation process, which included input from over 250 faculty, staff, and external stakeholders. Furthermore, the Pillar 3 focus areas are aligned with goals laid out in the original K-State 2025 strategic plan (https://www.k-state.edu/2025/).

\section{Summary}

To quote from our Pillar 3 strategic plan document submitted to KBOR: "K-State's Pillar 3 plan creates an initia- tive that will become a part of the university's long-term strategic plan and will be aligned with other related initiatives to increase efficiencies and impact and avoid duplication. The initiative will be focused on issues of primary importance to state policymakers and citizens of the state, jobs and prosperity. This initiative will connect university efforts directly to the national and international marketplace where jobs and prosperity are a match between our capabilities and market needs at a scope and scale that has never happened before. The institution will naturally evolve in ways to take full advantage of the initiative, the global marketplace, and the issues of importance to Kansans. As with any other innovative advancement, K-State of the 21st century will evolve at much greater velocity than ever before."

\section{References}

1. Wigginton, N. S., Cunningham, R. M., Katz, R. H., Lidstrom, M. E., Moler, K. A., Wirtz, D., \& Zuber, M. T. (2020). Moving academic research forward during COVID-19. Science, 368: 1190-1192.

2. Collins, C. (2020). Productivity in a pandemic. Science, 369: 603.

3. Carr, R. M., Lane-Fall, M. B., South, E., Brady, D., Momplaisir, F., Guerra, C. E., Montoya-Williams, D., Dalembert, G., Lavizzo-Mourey, R., \& Hamilton, R. (2021). Academic careers and the COVID-19 pandemic: Reversing the tide. Sci. Transl. Med., 13, eabe7189.

4. Kansas Board of Regents (2020). Building a Future: Higher Education's Commitment to Kansas Families, Businesses, and the Economy. https://www.kansasregents.org/about/ building-a-future

5. Kansas Department of Commerce (2021). Kansas Framework for Growth. https:// www.kansascommerce.gov/kansas-framework-for-growth/

6. Kottek, M., Grieser, J., Beck, C., Rudolf, B., \& Rubel, F. (2006). World Map of the Köppen-Geiger climate classification updated. Meteorol. Z., 15, 259-263. DOI: 10.1127/0941-2948/2006/0130. Accessed at: http://koeppen-geiger.vu-wien.ac.at/ present.htm 